\title{
Treatment of Advanced Kienbock's Disease (Lichtman Stage IIIB with Carpal Collapse) by a Shortening Osteotomy of the Radius: 21 Cases
}

\author{
${ }^{1}$ Department of Orthopaedics, Hospital dos Lusiadas, Lisbon, \\ Portugal \\ 2 Department of Orthopaedics, Hospital de Sant'Ana, Parede, \\ Portugal
}

J. C. Botelheiro, MD ${ }^{1}$ Silvia Silverio, MD ${ }^{2}$ Ana Luísa Neto, MD²

\begin{abstract}
Address for correspondence Ana Luísa Neto, MD, Department of Orthopaedics, Hospital de Sant'Ana, Parede 2779-501, Portugal (e-mail: analuisaneto.s@gmail.com).
\end{abstract}

J Wrist Surg 2019;8:264-267.

\begin{abstract}
Keywords

- Kienbock's disease

- carpal collapse

- radial osteotomy

Purpose To review the results of shortening osteotomies of the radius in our stage IIIB Kienbock's disease patients.

Materials and Methods In the past 30 years, we treated 52 cases of Kienbock's disease by a shortening osteotomy of the radius, of which 21 already had carpal collapse. All patient charts and X-rays were reviewed, but only the cases already with carpal collapse (stage IIIB) are presented here.

Results All patients improved after surgery. Pain, on a scale of 0 to 3, generally 2 or 3 before surgery (median: 2.3), was normally 1 or 0 afterward (median: 0.9); median flexion-extension of the wrist improved from 77 to 99 degrees; and grip strength of the other hand improved from 26 to $76 \%$. The last clinical and radiological review was performed 1 to 23 years after surgery (median: 8 years).

Conclusion Advanced Kienbock's disease with carpal collapse is not a contraindication for carpal-sparing surgery radial shortening osteotomy.
\end{abstract}

Kienbock's disease, also known as avascular necrosis of the lunate, was described in 1910 and classified into progressive radiological stages by Stahl and Decoulx. ${ }^{1}$ In Decoulx stages I and II, the lunate keeps its original form and volume, although with changes in radiological density, flattening of the lunate appears in stage III and there are already signs of radiocarpal osteoarthritis in stage IV. Lichtman later divided stage III into A, without carpal collapse, and B, already with carpal collapse. ${ }^{2}$

More recently, new classifications and staging of Kienbock's disease based on magnetic resonance imaging (MRI) and/or arthroscopy were introduced with theoretical therapeutic implications. $^{3-5}$

Conservative treatment of the symptomatic diseaseimmobilization-is generally not advised, ${ }^{6,7}$ except in very early cases or children and adolescents, ${ }^{5}$ and many surgical techniques have been used to treat Kienbock's disease. ${ }^{2,3}$
Hulten stated in 1928 that "cubitus minus" was more frequent in Kienbock's disease patients and would be the main cause of the disease. That led to the use of lengthening osteotomies of the ulna and shortening osteotomies of the radius in the treatment of Kienbock's disease, with good clinical results. ${ }^{1}$

Although that statement was challenged, ${ }^{8,9}$ biomechanical studies seem to prove that those osteotomies, in fact, lessen the pressure on the lunate bone. ${ }^{10,11}$ The shortening osteotomy of the radius, with less bone union problems than the lengthening osteotomy of the ulna, ${ }^{12}$ became probably the most popular surgery for Kienbock's disease around the world, ${ }^{3}$ sometimes combined with other techniques. ${ }^{13,14}$

Lichtman, following his radiological classification of Kienbock's disease, stated that with carpal collapse (stage IIIB) "equalization procedures, though they may unload the received

February 26, 2019

accepted

April 9, 2019

published online

May 28, 2019
Copyright $\odot 2019$ by Thieme Medical Publishers, Inc., 333 Seventh Avenue, New York, NY 10001, USA Tel: +1(212) 584-4662.
DOI https://doi.org/ 10.1055/s-0039-1688947. ISSN 2163-3916. 
lunate, are not likely to reestablish normal carpal architecture and mechanics." Therefore, for stage IIIB, scaphotrapeziotrapezoid or scaphocapitate fusion is recommended. If there is significant synovitis, then the lunate should be excised as well." ${ }^{2}$ This became a dogma for most hand surgeons ${ }^{15}$ despite the good clinical results published by many authors with radial osteotomies in advanced Kienbock's disease. $^{16-23}$

\section{Materials and Methods}

Since 1985 , the only surgical technique used primarily in our Kienbock's disease patients was radial shortening osteotomy (except cases already with radiocarpal osteoarthritis): 52 cases. All patients files were reviewed, but only the 21 cases with carpal collapse (Lichtman IIIB) are presented here (-Fig. 1).

After surgery, patients were asked to visit yearly for revision, but many, living far away, were lost to follow-up. They were all operated and reviewed by the first authors of this work. The last clinical and radiological revision was between 1 and 23 years (median: 8).

Only 7 were male, and only 8 left wrists were operated. Age was between 15 and 66 years (median: 32). Patients' complaints had started between 1 month and 3 years prior to presentation.

Pain was classified into the following:

- Grade 3 Nakamura: constant, 8 cases.

- Grade 2 Nakamura: even in light work, 12 cases.

- Grade 1 Nakamura: only in heavy work, 1 case.

- Grade 0 Nakamura: no pain, none.

Before surgery, median wrist mobility in flexion-extension was 77 degrees, and prehension strength, measured with a pneumatic manometer, was $26 \%$ of that of the other hand.
These measures were not tested in a spastic patient. ${ }^{24} \mathrm{~A}$ total of 15 patients were considered to have an "ulna minus" and 6 to have a neutral ulnar variance. ${ }^{2}$ Thirteen patients had fragmentation of the lunate bone seen in standard X-rays of the wrist ${ }^{25}$ : "Lichtman IIIC stage." ${ }^{26}$ Classification of the Kienbock's disease in stage IIIB (with carpal collapse) was done comparing to the contralateral wrist.

The shortening osteotomies of the radius $(2-3 \mathrm{~mm})$ were performed in the initial years using a dorsal approach in the distal metaphysis and fixation with a straight plate (two patients of this series). The last 19 patients were operated using a palmar approach, ${ }^{27}$ with the very distal osteotomy fixed with a T-plate (-Fig. 2). They were immobilized with an antebrachial plaster splint for 4 weeks and then started active mobilization for another month followed by formal physiotherapy, if needed. Work was resumed when a sound union was seen in X-rays, or even before in cases of light work. Three posterior interosseous neurotomies and one carpal tunnel release were performed with the osteotomies.

\section{Results}

According to our files review, all patients improved after surgery. Pain, generally 2 or 3 before surgery (median: 2.3 ), was normally 1 or 0 afterward (median: 0.9 ); median flexion-extension of the wrist improved from 77 to 99 degrees; and grip strength of the other hand improved from 26 to $76 \%$.

None of the six patients with neutral ulnar variance had lasting ulnar pain after surgery. That was only described with bigger radial shortening, ${ }^{28}$ but we must admit that in most of these cases, the distal shortening osteotomy was wedged wider on the radial side than on the ulnar one. ${ }^{29}$

Rather subjectively, X-rays were considered improved in just one patient, unchanged in 11 , and worsened in 9 , with no
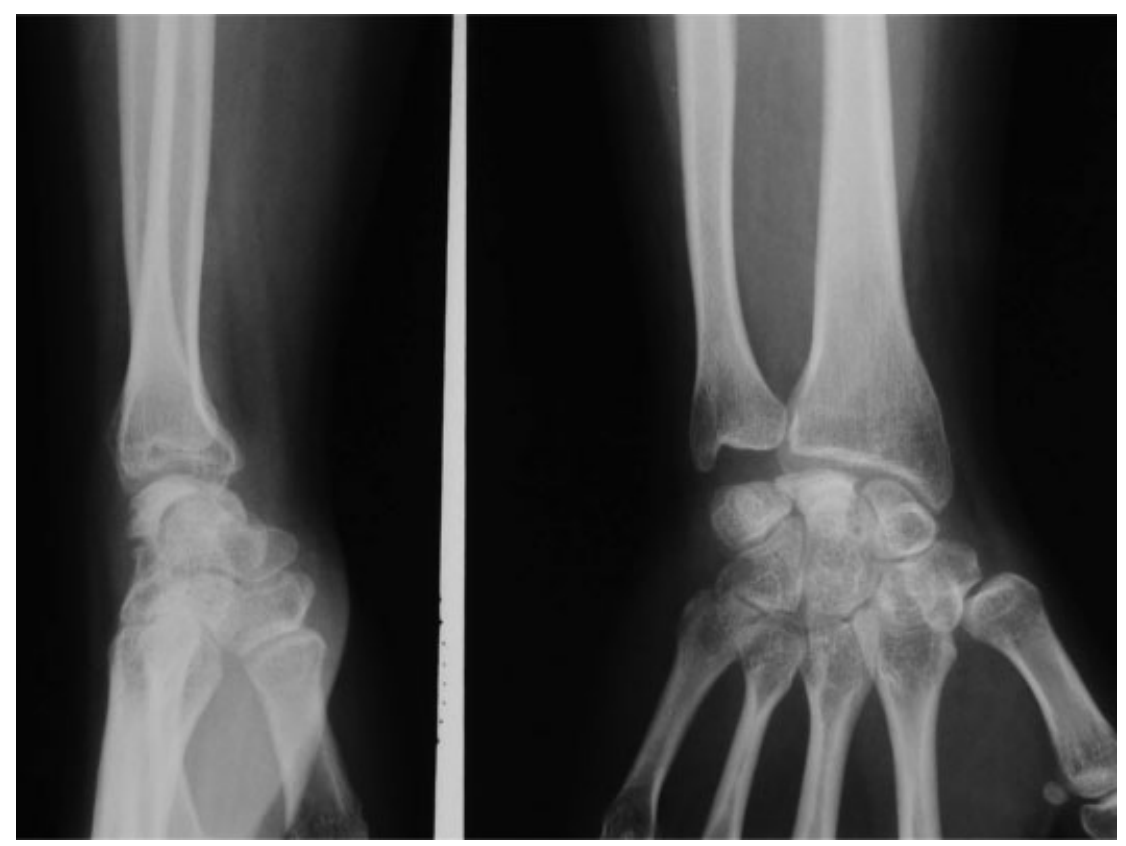

Fig. 1 Case 25: preoperative status and X-rays (1997, 22 years). Pain: 2, flexion-extension: 45 degrees; grip: 10\%. 

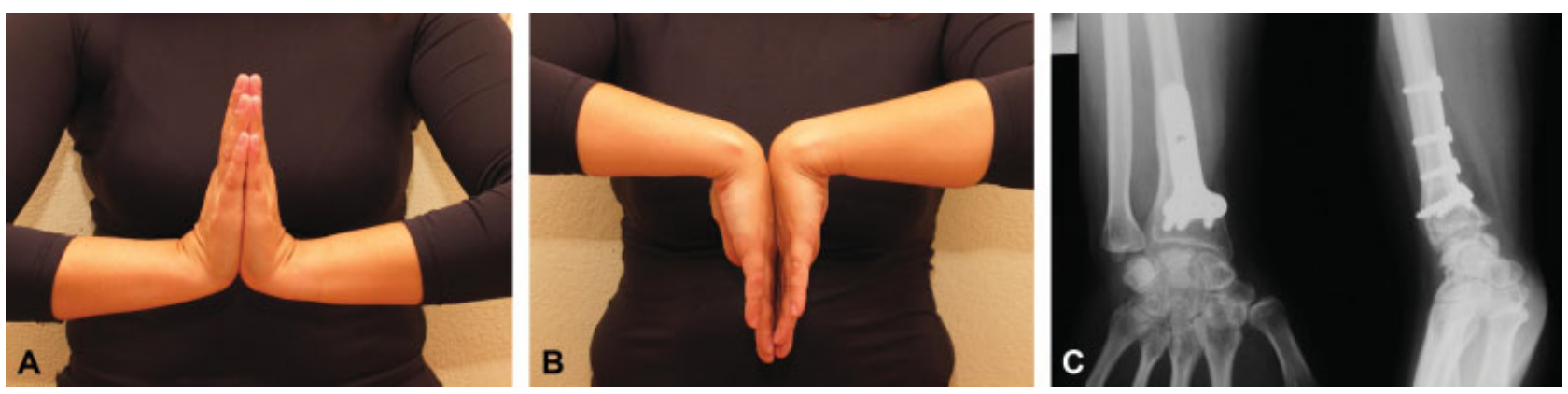

Fig. 2 Case 25: postoperative status and X-rays (2018). Pain: 1; flexion-extension: 110 degrees; grip: 80\%; light work.

correlation with clinical status. Four patients were reoperated: three with plate removals (two dorsal plates and one palmar) with posterior interosseous neurotomy and one with Phemister ${ }^{30}$ grafted delayed union (operated with a palmar plate) that united quickly with a good clinical result.

\section{Discussion and Conclusions}

Etiology and natural evolution of Kienbock's disease are largely unknown, ${ }^{31}$ and asymptomatic cases are rather frequent. $^{32,33}$ Carpal collapse in Kienbock's disease does not progress to radiocarpal osteoarthritis as in posttraumatic cases, ${ }^{34}$ probably because there are no abnormal movements between the carpal bones ${ }^{35}$-it is an adaptative carpal collapse, not a carpal instability. ${ }^{36}$

Intercarpal arthrodesis (with or without lunate excision) lessen wrist pain but also wrist mobility. ${ }^{37,38}$ Radial osteotomies lessen wrist pain and improve wrist mobility, and are probably more effective in increasing grip strength. ${ }^{38}$

These are the main reasons to avoid primary aggressive carpal surgery, such as carpal arthrodesis, proximal carpectomy, ${ }^{15,39}$ and others, ${ }^{40}$ in Kienbock's disease, even in cases with carpal collapse (Lichtman stage IIIB) or lunate fragmentation. ${ }^{25}$

Finally, any carpal surgery can be added to an eventually failed radial shortening osteotomy. ${ }^{41}$ As a conclusion, radial shortening osteotomy should not be contraindicated in advanced Kienbock's disease (without radiocarpal osteoarthritis), as stated, $2,5,15,26$ because it achieves long-lasting good clinical results, with very few complications.

\section{Conflict of Interest}

None declared.

\section{Acknowledgment}

The authors thank Dr. Joanne Charlton for her great help in the final English version of this work.

\section{References}

1 Axelson R, Moberg E. Le traitement de la maladie de Kienbock et le role des interventions de reequilibration radio-cubitale. In: Razemon JP, Fisk GR, eds. Le poignet: Monographies du G.E.M. Paris: Expansion Scientifique Francaise; 1983:210-217

2 Alexander AH, Lichtman DM. The Kienbock dilemma - how to cope. In: Nakamura R, Lischeid RL, Miura T, eds. Wrist Disorders -
Current Concepts and Challenges. Tokyo: Springer-Verlag; 1992: 79-88

3 Lamas C. La enfermedad de Kienbock. Barcelona J.M.. Bosch Editor 2005;100-2:123-135

4 Bain GI, Begg M. Arthroscopic assessment and classification of Kienbock's disease. Tech Hand Up Extrem Surg 2006;10(01):8-13

5 Lichtman DM, Pientka WF II, Bain GI. Kienböck disease: a new algorithm for the 21st century. J Wrist Surg 2017;6(01):2-10

6 Mikkelsen SS, Gelineck J. Poor function after nonoperative treatment of Kienböck's disease. Acta Orthop Scand 1987;58(03):241-243

7 Salmon J, Stanley JK, Trail IA. Kienböck's disease: conservative management versus radial shortening. J Bone Joint Surg Br 2000; 82(06):820-823

8 D'Hoore K, De Smet L, Verellen K, Vral J, Fabry G. Negative ulnar variance is not a risk factor for Kienböck's disease. J Hand Surg Am 1994;19(02):229-231

9 van Leeuwen WF, Oflazoglu K, Menendez ME, Ring D. Negative ulnar variance and Kienböck disease. J Hand Surg Am 2016;41 (02):214-218

10 Trumble T, Glisson RR, Seaber AV, Urbaniak JR. A biomechanical comparison of the methods for treating Kienböck's disease. J Hand Surg Am 1986;11(01):88-93

11 Horii E, Garcia-Elias M, Bishop AT, Cooney WP, Linscheid RL, Chao EY. Effect on force transmission across the carpus in procedures used to treat Kienböck's disease. J Hand Surg Am 1990;15(03): $393-400$

12 Trail IA, Linscheid RL, Quenzer DE, Scherer PA. Ulnar lengthening and radial recession procedures for Kienböck's disease. Long-term clinical and radiographic follow-up. J Hand Surg [Br] 1996;21(02): 169-176

13 Quenzer DE, Dobyns JH, Linscheid RL, Trail IA, Vidal MA. Radial recession osteotomy for Kienböck's disease. J Hand Surg Am 1997; 22(03):386-395

14 Mathoulin C, Wahegaonkar AL. Revascularization of the lunate by a volar vascularized bone graft and an osteotomy of the radius in treatment of the Kienböck's disease. Microsurgery 2009;29(05): 373-378

15 Danoff JR, Cuellar DO, O J, Strauch RJ. The management of Kienböck Disease: a survey of the ASSH membership. J Wrist Surg 2015;4(01):43-48

16 Gomis R, Martin B. Idoux, Chamas M et allieu Y: Maladie de Kienbock - traitement par osteotomie de racourcissement du radius. Rev Chir Orthop Repar Appar Mot 1994;80:196-204

17 Botelheiro JC. Treatment of Kienbock's disease by shortening osteotomy of the radius. Review of 20 cases. J Hand Surg Am 1997;22B(Suppl 1):48

18 Iwasaki N, Minami A, Oizumi N, Suenaga N, Kato H, Minami M. Radial osteotomy for late-stage Kienböck's disease. Wedge osteotomy versus radial shortening. J Bone Joint Surg Br 2002;84(05): 673-677

19 Altay T, Kaya A, Karapinar L, Ozturk H, Kayali C. Is radial shortening useful for Litchman stage 3B Kienbock's disease? Int Orthop 2008;32(06):747-752 
20 Calfee RP, Van Steyn MO, Gyuricza C, Adams A, Weiland AJ, Gelberman RH. Joint leveling for advanced Kienböck's disease. J Hand Surg Am 2010;35(12):1947-1954

21 Rodrigues-Pinto R, Freitas D, Costa LD, et al. Clinical and radiological results following radial osteotomy in patients with Kienböck's disease: four- to 18-year follow-up. J Bone Joint Surg Br 2012;94(02):222-226

22 Mozaffarian K, Namazi H, Namdari A. Radial shortening osteotomy in advanced stages of Kienbock disease. Tech Hand Up Extrem Surg 2012;16(04):242-246

23 Shin YH, Kim J, Gong HS, Rhee SH, Cho MJ, Baek GH. Clinical outcome of lateral wedge osteotomy of the radius in advanced stages of Kienböck's disease. Clin Orthop Surg 2017;9(03):355-362

24 Rooker GD, Goodfellow JW. Maladie de Kienbock chez les infirmes moteurs. cérébraux. In: Le poignet. Paris: Expansion Cientifique Française; 1983

25 Tatebe M, Hirata H, Iwata Y, Hattori T, Nakamura R. Limited wrist arthrodesis versus radial osteotomy for advanced Kienböck's disease-for a fragmented lunate. Hand Surg 2006;11(1-2):9-14

26 Lichtman DM, Lesley NE, Simmons SP. The classification and treatment of Kienbock's disease: the state of the art and a look at the future. J Hand Surg Eur Vol 2010;35(07):549-554

27 Botelheiro JC, Guia EM. Plating the palmar surface of the distal radius in shortening osteotomies for Kienböck's disease and Barton's fracture. J Hand Surg [Br] 1996;21(06):833

28 Nakamura R, Imaeda T, Miura T. Radial shortening for Kienböck's disease: factors affecting the operative result. J Hand Surg $[\mathrm{Br}]$ 1990;15(01):40-45

29 Watanabe K, Nakamura R, Horii E, Miura T. Biomechanical analysis of radial wedge osteotomy for the treatment of Kienböck's disease. J Hand Surg Am 1993;18(04):686-690

30 Phemister DB. Treatment of ununited fractures by onlay bone grafts without screw or tie fixation and without breaking down of the fibrous union. J Bone Joint Surg Am 1947;29(04): 946-960
31 Stahl S, Lotter O, Santos Stahl A, et al. 100 years after Kienböck's description: review of the etiology of Kienböck's disease from a historical perspective [in German]. Orthopade 2012;41(01):66-72

32 Golay SK, Rust P, Ring D. The radiological prevalence of incidental Kienböck disease. Arch Bone Jt Surg 2016;4(03):220-223

33 van Leeuwen WF, Janssen SJ, ter Meulen DP, Ring D. What is the radiographic prevalence of incidental Kienböck disease? Clin Orthop Relat Res 2016;474(03):808-813

34 Taniguchi Y, Tamaki T, Honda T, Yoshida M. Rotatory subluxation of the scaphoid in Kienböck's disease is not a cause of scapholunate advanced collapse (SLAC) in the wrist. J Bone Joint Surg $\mathrm{Br}$ 2002;84(05):684-687

35 Dias JJ, Lunn P. Ten questions on Kienbock's disease of the lunate. J Hand Surg Eur Vol 2010;35(07):538-543

36 Garcia-Elias M, Lluch AL. Wrist instabilities, misalignements and dislocations. In: Wolfe SW, Hotchkiss RN, Pederson WC, Kozin SH, Cohen MS, eds, Green's Operative Hand Surgery. 7th ed. Philadelphia, PA: Elsevier; 2017:464

37 Voche P, Bour C, Merle M. Scapho-trapezio-trapezoid arthrodesis in the treatment of Kienböck's disease. A study of 16 cases. J Hand Surg Br 1992;17(01):5-11

38 Das Gupta K, Tünnerhoff HG, Haussmann P. STT-arthrodesis versus radial shortening osteotomy for Kienböck's disease [in German]. Handchir Mikrochir Plast Chir 2003;35(05):328-332

39 Croog AS, Stern PJ. Proximal row carpectomy for advanced Kienböck's disease: average 10-year follow-up. J Hand Surg Am 2008;33(07):1122-1130

40 Mir X, Barrera-Ochoa S, Lluch A, et al. New surgical approach to advanced Kienböck disease: lunate replacement with pedicled vascularized scaphoid graft and radioscaphoidal partial arthrodesis. Tech Hand Up Extrem Surg 2013;17(02):72-79

41 Kakinoki R, Yamakawa T, Nakayama K, Morimoto Y, Nakamura T. Treatment of progressive necrosis of the lunate bone (Kienböck disease) after unsuccessful radial osteotomy. Scand J Plast Reconstr Surg Hand Surg 2007;41(05):267-271 